\title{
Phytochemical analysis, antioxidant, antibacterial, and cytotoxic activities of leaves and roots of Rubus hyrcanus Juz.
}

\author{
Fatemeh Yousefbeyk ${ }^{1}$-Saeed Ghasemi ${ }^{2} \cdot$ Mehdi Evazalipour $^{3} \cdot$ Sara Dabirian $^{3} \cdot$ Clara Schubert $^{4} \cdot$ Sanaz Hekmatnia $^{1}$. \\ Yasamin Habibi ${ }^{1}$. Diba Eghbali Koohi ${ }^{1}$ - Volker Böhm ${ }^{4}$ (1)
}

Received: 30 June 2021 / Revised: 16 September 2021 / Accepted: 18 September 2021 / Published online: 26 September 2021

(c) The Author(s) 2021

\begin{abstract}
Rubus hyrcanus Juz. (Rosaceae), known as Caspian blackberry, is wildly distributed around the Caspian Sea. This study focused on antioxidant, cytotoxic, and antibacterial activities of total extracts and different fractions from the roots and leaves of this species. The total phenolics and flavonoid contents were also evaluated. Finally, the phenolic profiles of selected fractions were determined using HPLC-DAD and LC-MS/MS. The results indicated that the total phenolics content (TPC) of root total extract (RTE) was 3.5 times that of leaves (340.4 and $102.7 \mathrm{mg} \mathrm{GAE} / \mathrm{g}$, respectively). The TPC of three root fractions ranged from 226.6 to $392.9 \mathrm{mg} \mathrm{GAE} / \mathrm{g}$, while in leaves fractions, it ranged between 68.3 and $101.8 \mathrm{mg} \mathrm{GAE} / \mathrm{g}$. The total extract of leaves had higher contents of total flavonoids than roots (70.5 and $8.9 \mathrm{mg} Q E / g$, respectively). The methanol fractions of both parts had the highest amounts of flavonoids. The root methanol fraction (RMF) had the best antioxidant effect in both DPPH radical scavenging assay $\left(\mathrm{IC}_{50}: 9.16 \mu \mathrm{g} \mathrm{ml}^{-1}\right)$ and total antioxidant capacity test $(1010.5 \mathrm{mg} \mathrm{aTE} / \mathrm{g})$. The RMF and RTE had potent antibacterial activities against Bacillus subtilis and Staphylococcus aureus (MIC $1.5 \mathrm{mg} \mathrm{ml}^{-1}$ ). In the MTT assay, ethyl acetate fractions of roots and leaves exhibited the best cytotoxicity $\left(\mathrm{IC}_{50} 247\right.$ and $227 \mu \mathrm{g} \mathrm{ml}{ }^{-1}$, respectively) and the highest selectivity indexes ( 4.73 and 5.31, respectively). Phytochemical analysis revealed the presence of gallic acid, p-coumaric acid, and chlorogenic acid in leaves ethyl acetate fraction, chlorogenic acid in leaves methanol fraction, and gallic acid in the root ethyl acetate fraction.
\end{abstract}

Keywords Blackberry $\cdot$ Radical scavenging activity $\cdot$ Antibacterial effect $\cdot$ Cytotoxicity $\cdot$ Total phenolics $\cdot$ Total flavonoids

\section{Introduction}

Oxidative stress, defined as an imbalance between the production of oxidative agents and antioxidant systems, can lead to oxidative damage to the macromolecules like lipids, proteins, and nucleic acids [1-3]. It plays a significant role in developing several degenerative diseases, including diabetes,

Volker Böhm

volker.boehm@uni-jena.de

1 Department of Pharmacognosy, School of Pharmacy, Guilan University of Medical Sciences, Rasht, Iran

2 Department of Medicinal Chemistry, School of Pharmacy, Guilan University of Medical Sciences, Rasht, Iran

3 Department of Pharmaceutical Biotechnology, School of Pharmacy, Guilan University of Medical Sciences, Rasht, Iran

4 Institute of Nutritional Sciences, Friedrich Schiller University Jena, Jena, Germany rheumatoid arthritis, cardiovascular diseases, cancer, brain, immune system dysfunction, and aging [4, 5]. To overcome the cellular damage caused by free radicals and other associated reactive oxygen species (ROS), a very complicated endogenous antioxidant system is evolved in human beings. In addition, there are a vast number of exogenous antioxidants that contribute to neutralizing free radicals $[4,6,7]$. Medicinal and dietary plants, fruits, and vegetables are rich sources of natural antioxidants that can inhibit oxidative damage and bring health benefits by scavenging reactive free radicals [8]. Furthermore, the utilization of antioxidant preservatives in the food industry helps to keep freshness and avoids browning and rancidity, especially in lipids and lipid-containing products, inhibiting/delaying deterioration of products during processing, transportation, and storage [9].

Among different natural antioxidants, phenolic compounds consist of a large group of phytochemicals in plant's species that have a wide range of structures and 
functions [10]. The polyphenols are characterized by one or more hydroxyl-containing aromatic rings, resulting in simple phenolic molecules or highly polymerized structures. Because of their chemical structures, polyphenols have a high antioxidant capacity [11]. They support the human antioxidant system by acting as reactive oxygen scavengers, metal chelators, and enzyme modulators [12].

Medicinal plants have been historically used for their antibacterial properties against food-borne bacteria and food spoilage pathogens to improve the safety of products and prolong their shelf life [13]. Bacteria such as Bacillus subtilis, Staphylococcus aureus, Escherichia coli, and Pseudomonas aeruginosa are widespread food-borne and food spoilage bacteria that can cause diseases [14-16]. Phytochemicals such as polyphenols, alkaloids, lectins, terpenoids, polypeptides, and polyacetylenes are wellknown for their antimicrobial effects [13]. Among them, various phenolic compounds exhibit potent antibacterial activity and, therefore have attracted attention as a natural replacement of synthetic preservatives in the food industry [17]. The mechanism of such activity can be due to the alteration of cell membrane permeability, losing integrity, changing the cell wall rigidity, and the modifications of several intracellular functions such as hydrogen binding between polyphenols and bacterial enzymes [17].

The genus Rubus (Rosaceae) comprises over 750 species and is one of the most diverse genera of plants, broadly distributed in the world as wild and cultivated species and genotypes $[18,19]$. Among them, Rubus hyrcanus Juz., commonly known as Caspian blackberry, is an important wild blackberry species distributed around the Caspian Sea [20]. Leaves and fruits of Rubus species have been used in numerous countries as natural medicines to treat a number of diseases like diabetes, many types of infections, colic, and burns. The leaves of some species also have been administrated in traditional folk medicine as antispasmodic, antidiarrheal, anti-inflammatory for oral and throat diseases, anti-morning sickness, anti-headache, uterine relaxant, insecticidal, and wound treatment agent [19, 21-23].

Moreover, the roots of some species like $R$. fruticosus have been used for the treatment of diarrhea and labor pain [24]. The roots' decoction has astringent, tonic, and wound healing properties [25].

Today, discovery of antioxidant and antibacterial agents from edible plants rich in polyphenols is of great interest. In this study, the total phenolic and flavonoid contents of total extracts and fractions from leaves and roots of $R$. hyrcanus were determined. The antioxidant, antibacterial and cytotoxic activities were evaluated. Finally, the detection and classification of the polyphenols in the fractions with the highest antioxidant and antibacterial capacities were carried out using HPLC-DAD and LC-MS/MS.

\section{Materials and methods}

\section{Chemicals}

Quercetin, gallic acid, 2,2-diphenyl-1-picrylhydrazyl $\left(\mathrm{DPPH}^{\bullet}\right)$, Folin-Ciocalteu's phenol reagent, BHA (butylated hydroxyanisole), and vitamin E were bought from SigmaAldrich, USA. Aluminum trichloride $\left(\mathrm{AlCl}_{3}\right)$, ammonium molybdate tetrahydrate, and sodium bicarbonate were got from Merck, Germany. External standards used for HPLC analysis were obtained from Carl Roth, Sigma Aldrich, Alfa Aesar, and Altmann Analytik, Germany. HPLC-grade acetonitrile was purchased from Th. Geyer, Germany. The acetic acid was from Altmann Analytik, Germany. The cancerous and normal cell lines (MCF-7 and HU02) were bought from the Iranian Biological Resource Center. Dulbecco's Modified Eagle Medium (DMEM) was obtained from Gibco. Fetal bovine serum (FBS) was purchased from Invitrogen. Other used reagents and solvents were of analytical grade.

\section{Plant materials, extraction, and fractionation}

The aerial parts and roots of $R$. hyrcanus were collected from Fouman-Saravan highway, Guilan province, Iran, in May and September 2019, respectively. The voucher specimen (113 HGUM) was deposited in the herbarium of the School of Pharmacy, Guilan University of Medical Sciences. The leaves and roots were separated and shade-dried at room temperature for a week. The leaves and roots $(500 \mathrm{~g}$, each) were powdered in a mixer grinder and extracted with methanol by percolation method for $24 \mathrm{~h}(1000 \mathrm{ml})$. Extraction was repeated three times. The solvent was evaporated using a rotary vacuum evaporator at $40{ }^{\circ} \mathrm{C}$ to obtain the dried extract with extraction yield of $22 \%$ and $10 \%$, respectively. The dry extracts were stored at $4{ }^{\circ} \mathrm{C}$ until the analyses. The total extracts from each part of the plant were fractionated by solvents with different polarities, including hexane, ethyl acetate, and methanol, sequentially. The fractions were concentrated under reduced pressure by a rotary vacuum evaporator.

\section{Determination of total phenolics and total flavanoids}

The Folin-Ciocalteu assay was used to measure the total phenolic content of samples according to the method described previously [26,27]. This test was performed by mixing $1 \mathrm{ml}$ of each sample with $5 \mathrm{ml}$ of freshly prepared Folin-Ciocalteu reagent (diluted tenfold with distilled water) and incubated for $10 \mathrm{~min}$. Then, each solution was mixed with $4 \mathrm{ml}$ sodium bicarbonate solution $\left(75 \mathrm{~g} . \mathrm{l}^{-1}\right)$. After $30 \mathrm{~min}$, the absorbance 
was taken at $765 \mathrm{~nm}$ using a UV/vis spectrophotometer (LAMBDA 25, PerkinElmer) [27]. Gallic acid (GA) was used as the reference standard, and the following calibration curve was plotted: $y=0.00093 x-0.0375, R^{2}=0.999$. Total phenolics contents are expressed as $\mathrm{mg}$ of gallic acid equivalents (GAE) per gram of dry extract [28].

The measurement of flavonoid content was carried out by a method described by Saeidnia and Gohari (2012) [29, 30]. In the beginning, $5 \mathrm{ml}$ of aluminum trichloride $\left(\mathrm{AlCl}_{3}\right)$ ( $2 \%$ in methanol) was added to $5 \mathrm{ml}$ of each sample and vortexed well. After $10 \mathrm{~min}$, the absorbance of the mixture was measured at $415 \mathrm{~nm}$. The flavonoid quercetin was used as the standard substance, and the following calibration curve was plotted: $y=0.0179 x-0.0261, R^{2}=0.986$. Finally, the total flavonoid content is expressed as $\mathrm{mg}$ of quercetin equivalents $(\mathrm{QE}) / \mathrm{g}$ of extract.

\section{Determination of DPPH radical scavenging capacity}

The 2,2'-diphenyl-1-picrylhydrazyl (DPPH) free radical scavenging assay was carried out to investigate the radical scavenging activities of samples [28, 31]. Briefly, $2 \mathrm{ml}$ of DPPH methanol solution ( $40 \mu \mathrm{g} . \mathrm{ml}^{-1}$, freshly prepared) was added to $1 \mathrm{ml}$ of each sample. The absorbance was measured after $30 \mathrm{~min}$ at $\lambda_{\max } 517 \mathrm{~nm}$. Butylated hydroxyanisole (BHA) and vitamin $\mathrm{E}$ were used as the standard antioxidants. The control contained sample $(1 \mathrm{ml})$ and distilled water $(2 \mathrm{ml})$. The blank included DPPH solution $(2 \mathrm{ml})$ and distilled water $(1 \mathrm{ml})$. All the experiments were repeated three times. The percentage of scavenging was calculated using the following formula [32]:
The total antioxidant capacity of each sample is expressed as $\mathrm{mg}$ of $\alpha$-tocopherol equivalent ( $\alpha \mathrm{TE}$ ) per gram of extract, using the following linear equation plotted using $\alpha$-tocopherol as the standard: $y=0.0024 \mathrm{X}+0.004 ; R^{2}=0.998$. In this equation, $Y$ is the absorbance at $695 \mathrm{~nm}$, and $X$ is the concentration as $\alpha \mathrm{TE}\left(\mu \mathrm{g} \mathrm{ml}^{-1}\right)$.

\section{Cytotoxicity assay}

All samples were tested for their anti-proliferative activities against MCF-7 (breast cancer) and HU02 (human foreskin fibroblast) cell lines by MTT (3-(4,5-dimethyl-thiazol-2-yl)2,5-diphenyltetrazolium bromide) assay. In this assay, $5 \times 10^{3}$ cells per well were seeded in a 96-well plate in complete DMEM, incubated at $37{ }^{\circ} \mathrm{C}$ for $24 \mathrm{~h}$ in a humidified atmosphere containing $5 \% \mathrm{CO}_{2}$. After removing non-adherent cells, the adherent cells were exposed to six concentrations of each sample $\left(62.5,125,250,500,1000\right.$, and $\left.2000 \mu \mathrm{g} \cdot \mathrm{ml}^{-1}\right)$. Next, the cell lines were incubated for $48 \mathrm{~h}$ at $37^{\circ} \mathrm{C}$ with $5 \%$ $\mathrm{CO}_{2}$. The negative control was the growth medium without plant extract. Afterward, $20 \mu \mathrm{l}$ MTT solution $\left(5 \mathrm{mg} \cdot \mathrm{ml}^{-1}\right.$ in phosphate-buffered saline (PBS)) and DMEM $(180 \mu \mathrm{l})$ were added to each well, incubating for $4 \mathrm{~h}$. Then, supernatants were removed from the wells, and DMSO (150 $\mu$ l, each well) was used to dissolve formazan crystals [36]. The plates were placed on a shaker for $10 \mathrm{~min}$. The amount of purple formazan dye is directly associated with the number of vital cells in the culture $[36,37]$. The optical density (OD) was determined at $490 \mathrm{~nm}$ by an absorbance microplate reader (BioTek), using a reference wavelength of $630 \mathrm{~nm}$. Each MTT assay was carried out three times. The percentage of viable cells was determined using

$\%$ Scavenging $=100-\left[\frac{(\text { sample absorption }- \text { control absorption })}{\text { blank absorption }}\right] \times 100$.

The radical scavenging activities are expressed as $\mathrm{IC}_{50}$ values by plotting the percentage of scavenging against the sample concentrations.

\section{Determination of total antioxidant capacity by phosphomolybdenum reduction assay (PRA)}

The total antioxidant activities of the total extracts and fractions of $R$. hyrcanus were determined by the phosphomolybdenum reduction assay (PRA) $[33,34]$. In this method, the samples reduce $\mathrm{Mo}(\mathrm{VI})$ to $\mathrm{Mo}(\mathrm{V})$, forming specific green phosphate-Mo(V) compounds at acidic $\mathrm{pH}$. Briefly, $0.3 \mathrm{ml}$ of each sample was combined with $3 \mathrm{ml}$ of a reagent mixture (0.6 M sulfuric acid, $28 \mathrm{mM}$ sodium phosphate, and $4 \mathrm{mM}$ ammonium molybdate) in a test tube and incubated in an oil bath at $95^{\circ} \mathrm{C}$ for $90 \mathrm{~min}$. After cooling to room temperature, the absorbance of each mixture was measured at $695 \mathrm{~nm}$ [35]. the following equation:

$\%$ Viability $=\left(\frac{[\text { OD treated group }- \text { OD background }]}{[\text { OD control }- \text { OD background }]}\right) \times 100$.

The $\mathrm{IC}_{50}$ value was defined as the concentration of samples required for the reduction of cell viability by half and calculated using non-linear regression curves plotted by GraphPad Prism (Version 8, GraphPad Software, USA) [38, 39].

\section{Antibacterial assay}

Antimicrobial activities of total extracts and fractions prepared from leaves and roots of $R$. hyrcanus were tested against some food-borne and food-spoilage bacteria, including two Gram-positive (Staphylococcus aureus ATCC 6538 and Bacillus subtilis ATCC 9634) and two Gram-negative 
(Escherichia coli ATCC 8739 and Pseudomonas aeruginosa ATCC 9027) bacteria. The agar disk diffusion assay was used to determine the antibacterial activities. In this method, the bacterial inoculums were standardized to match the 0.5 McFarland (turbidity) standards in which bacterial density was set to be $1.5 \times 10^{8} \mathrm{CFU} \mathrm{ml}{ }^{-1}$. Afterward, the Petri dishes with $25 \mathrm{ml}$ Mueller Hinton agar (MHA) were seeded with test strain suspension using a sterile cotton swab. Discs were placed in the agar. The fully dried extracts and fractions were solved in water, in a concentration of $300 \mathrm{mg} \mathrm{ml}^{-1}$, and then $15 \mu \mathrm{l}$ of each sample was placed on each disk. After plates being incubated at $37{ }^{\circ} \mathrm{C}$ for $24 \mathrm{~h}$, they were evaluated for inhibition zones $(\mathrm{mm})$.

Minimum inhibitory concentration (MIC) was measured by the broth microdilution method using $96 \mathrm{U}$-shaped well plates [40]. First, a stock concentration was prepared from each sample in distilled water. Then, twofold serial dilution of each sample's stock solution $(100 \mu \mathrm{l})$ was prepared using Mueller Hinton broth (MHB) in wells. The serial dilutions of samples (10 concentrations from 100 to $0.8 \mathrm{mg} \mathrm{ml}^{-1}$ ) were prepared in microplates. Each bacteria inoculum $\left(1.5 \times 10^{8} \mathrm{CFU} \mathrm{ml^{-1 }}\right)$ was diluted in $0.9 \%$ saline to give $10^{6} \mathrm{CFU} \mathrm{ml}{ }^{-1}$. The plates were spot-inoculated with $100 \mu \mathrm{l}$ of each prepared bacterial suspension $\left(10^{5} \mathrm{CFU} / \mathrm{spot}\right)$. The bacteria were incubated at $37^{\circ} \mathrm{C}$ for $24 \mathrm{~h}$. The plates were tested for the absence or presence of visible growth compared to the negative control wells. The endpoint of MIC was the lowest concentration of the samples with no visible growth [41].

\section{HPLC-DAD analysis}

The concentrations of polyphenols in the fractions with the best biological activities (RMF, REF, LEF, and LMF) were determined by liquid chromatography. The method was adapted according to Kschonsek et al. [42]. For this purpose, a binary RP-HPLC gradient method was used. The column was a C18 (2)-Luna analytical column $(250 \times 4.6 \mathrm{~mm} ; 5 \mu \mathrm{m}$; Phenomenex Ltd, Aschaffenburg, Germany). The column temperature was $30{ }^{\circ} \mathrm{C}$. The mobile phase was composed of a time-varying ratio of $0.1 \%$ acetic acid in water (solvent $\mathrm{A}$ ) and methanol (solvent $B$ ). The flow rate of $0.8 \mathrm{ml} \mathrm{min}{ }^{-1}$ was used for a total run time of $160 \mathrm{~min}$. Elution was carried out using the following gradient program: $0-2 \mathrm{~min}, 0 \% \mathrm{~B}$ isocratic; 2-6 min, linear gradient from 0 to $15 \% \mathrm{~B} ; 6-12 \mathrm{~min}$, $15 \% \mathrm{~B}$ isocratic; $12-17 \mathrm{~min}$, linear gradient from 15 to $20 \% \mathrm{~B} ; 17-35 \mathrm{~min}, 20 \% \mathrm{~B}$ isocratic; 35-90 min, linear gradient from 20 to $35 \% \mathrm{~B}$; $90-132 \mathrm{~min}, 35 \% \mathrm{~B}$ isocratic, 132-150 min, linear gradient from 35 to $80 \% \mathrm{~B}$, 150-160 min linear gradient from 80 to $0 \%$ B [42]. The detection was performed by a DAD (diode array detector, $254 \mathrm{~nm}, 280 \mathrm{~nm}, 320 \mathrm{~nm}, 376 \mathrm{~nm}$; Merck-Hitachi,
Darmstadt, Germany). Identification was given by comparing retention times and DAD absorbance spectra with the external standards. The concentrations were calculated using five-point calibration curves of external standards. The linearity was given over the five-point calibration curve. The used standard phenolic compounds were caffeic acid, chlorogenic acid, 2,5-Dimethoxybenzoic acid, ellagic acid, ferulic acid, gallic acid, sinapinic acid, syringic acid, vanillic acid, p-coumaric acid, (-)-epicatechin, epicatechin gallate, epigallocatechin, epigallocatechin gallate; isoquercitrin, kaempferol, quercetin, rutin trihydrate, and luteolin-7-O-glucoside.

\section{LC-MS/MS analysis}

LC-MS/MS analysis was performed to identify unknown polyphenolic compounds in the plant samples. The detection was done using an API 2000 MS/MS system (AB Sciex, Darmstadt, Germany). The method was modified according to Ernawita et al. [43]. To detect polyphenols, a negative ion mode (APCI) was used with nitrogen as the nebulizer gas and a vaporizer temperature of $400^{\circ} \mathrm{C}$. The chromatographic separation was performed at $30^{\circ} \mathrm{C}$ on a Kinetex $\mathrm{C} 18$ column $(150 \times 2.1 \mathrm{~mm}, 5 \mu \mathrm{m}$, Phenomenex Ltd, Aschaffenburg, Germany) and a C18 guard column $(4 \times 30 \mathrm{~mm}$; Phenomenex Ltd, Aschaffenburg, Germany). The mobile phase consisted of a time-varying ratio of $0.3 \%$ formic acid in water (solvent A) and acetonitrile (solvent B). The gradient setting was as follow:

0-2 min, 90\% B isocratic; 2-12 min, linear gradient from 90 to $80 \% \mathrm{~B} ; 12-22 \mathrm{~min}$, linear gradient from 80 to $65 \% \mathrm{~B}$; 22-25 min, 65\% B isocratic; $25-27$ min, linear gradient from 65 to $90 \% \mathrm{~B} ; 27-37 \mathrm{~min}, 90 \% \mathrm{~B}$ isocratic. The detection was performed by a UV detector $(280 \mathrm{~nm}$; Shimadzu, Duisburg, Germany). Identification was obtained using a Multiple Ion Scan. For verification, multiple reactions monitoring (MRM) was performed, and the mass-to-charge ratios of the resulting fragments were compared with values from the literature. The confirmation of the polyphenols was given using their respective standards. Mass spectra of unknown phenolic compounds were acquired using a 200-600 scan range.

\section{Statistical analysis}

Every experiment was performed in triplicates. All the results are expressed as mean \pm standard deviation (SD). The correlation between phytochemicals and antioxidant activity was tested by Pearson correlation coefficient, using the SPSS program (Version 22.0. SPSS Inc., Chicago, USA). $p$ values $<0.05$ were considered significant. 


\section{Results and discussion}

\section{Total phenolics and flavonoids contents}

The total phenolics content (TPC) of roots and leaves of $R$. hyrcanus was determined by the Folin-Ciocalteu method. As is presented in Table 1, the phenolics content of root total extract (RTE) was 3.5 times that of leaves total extract (LTE) (340.4 and $102.7 \mathrm{mg} \mathrm{GAE} / \mathrm{g}$ extract, respectively). The TPC of three root fractions ranged from 226.6 to $392.9 \mathrm{mg} \mathrm{GAE} / \mathrm{g}$ extract, while it ranged between 68.3 and $101.8 \mathrm{mg} \mathrm{GAE} / \mathrm{g}$ extract in leaf samples. Among the three solvents used for fractionation, methanol revealed the highest amounts of phenolic compounds in both roots and leaves, followed by ethyl acetate and hexane. The results specified that methanol was more selective for fractionation of the phenolic compounds in $R$. hyrcanus leaves and roots than the other two solvents.

Pavlovic et al. exhibited that the total phenolics content in leaves methanol extract of three cultivars of $R$. idaeus ranged from 84.6 to $144.2 \mathrm{mg} \mathrm{GAE} / \mathrm{g}$. The results of our study are in the range of that study [44]. Veljkovic et al. investigated the total phenolics contents in leaves of different populations of $R$. idaeus growing in Serbia, and the results ranged from 59.7 to $96.8 \mathrm{mg} \mathrm{GAE} / \mathrm{g}$ [45]. Venskutonis et al. evaluated the leaves of $R$. idaeus, collected in several geographical locations in Lithuania, and reported that the amount of total phenolics varied from 4.8 to $12.0 \mathrm{mg} \mathrm{GAE} / \mathrm{g}$ [23]. Asnaashari et al. determined that the amount of TPC in leaves of $R$. fruticosus ranged from 57.6 to $108.6 \mathrm{mg} \mathrm{GAE} / \mathrm{g}$ and the methanol extract had the highest concentration of phenolic compounds.
In all samples, the flavonoid content of leaves was higher than of roots. In leaves samples, the LTE had the highest amount of flavonoids (70.5 mg QE/g extract), followed by LMF (62.6 mg QE/g extract). In root samples, the RTE and RMF had the highest amount of flavonoids (8.89 and $7.54 \mathrm{mg} \mathrm{QE/g} \mathrm{extract)} \mathrm{[46].} \mathrm{In} \mathrm{other} \mathrm{studies,} \mathrm{dif-}$ ferent flavonoids have been reported in the leaves of Rubus species, including quercetin, kaempferol, hyperosid, rutin, and quercetin 3-O- $\beta$-d-glucopyranoside $[22,47]$. Studies revealed the presence of several phenolic compounds in the root acetone fraction of $R$. fairholmianus. Compounds such as 1-(2-Hydroxyphenyl)-4-methylpentan-1-one, 2-[(3-Methylbutoxy)carbonyl] benzoic acid, 2-(5-Methylhexyl) benzoic acid, 4-Methylpentyl benzoate, 3-(Iminomethyl)-2,4-dimethylphenol, and 3-Methylbutyl benzoate have been isolated from this species and showed strong antioxidant effects [19, 48].

Generally, studies have suggested that the highest amount of phenolic compounds, known as plant defense secondary metabolites, in roots can be connected to lignification of root tissues in order to provide better resistance and hardness, lower tissue elasticity, and acting as an effective physical barrier to soil pathogens. However, it is demonstrated that in leaves, light can stimulate the synthesis of flavonoids as they have the protective role against UV rays damages [49].

\section{Antioxidant capacity}

Due to the presence of phenolic compounds, leaves and roots of $R$. hyrcanus showed wide ranges of radical scavenging activities. The extract and fractions prepared from root exhibited significant DPPH radical scavenging activity (ranged from $\mathrm{IC}_{50} 9.2$ to $13.3 \mu \mathrm{g} \mathrm{ml}^{-1}$ ). However, the leaves
Table 1 Total phenolics and flavonoid contents, and antioxidant activities of total extracts and different fractions from leaves and roots of Rubus hyrcanus

\begin{tabular}{|c|c|c|c|c|}
\hline & ТPC & TFC & DPPH & PRA \\
\hline \multicolumn{5}{|l|}{ Leaves } \\
\hline $\mathrm{TE}$ & $102.66 \pm 0.32$ & $70.45 \pm 0.02$ & $30.15 \pm 1.11$ & $571.00 \pm 0.12$ \\
\hline $\mathrm{HF}$ & $68.30 \pm 0.14$ & $12.05 \pm 0.01$ & $122.87 \pm 2.45$ & $447.14 \pm 0.03$ \\
\hline $\mathrm{EF}$ & $82.54 \pm 0.23$ & $47.11 \pm 0.04$ & $47.74 \pm 1.23$ & $474.92 \pm 0.14$ \\
\hline MF & $101.82 \pm 0.09$ & $62.57 \pm 0.04$ & $36.54 \pm 0.79$ & $558.75 \pm 0.05$ \\
\hline \multicolumn{5}{|l|}{ Roots } \\
\hline $\mathrm{TE}$ & $340.39 \pm 0.02$ & $8.89 \pm 0.01$ & $10.00 \pm 0.02$ & $941.00 \pm 0.54$ \\
\hline $\mathrm{HF}$ & $226.58 \pm 0.02$ & $4.55 \pm 0.01$ & $13.25 \pm 0.02$ & $880.16 \pm 0.05$ \\
\hline $\mathrm{EF}$ & $292.32 \pm 0.02$ & $7.38 \pm 0.02$ & $11.10 \pm 0.02$ & $960.00 \pm 0.02$ \\
\hline MF & $392.88 \pm 0.04$ & $7.54 \pm 0.01$ & $9.16 \pm 0.04$ & $1010.5 \pm 0.05$ \\
\hline BHA & - & - & $7.81 \pm 0.02$ & - \\
\hline Vitamin E & - & - & $14.20 \pm 0.01$ & - \\
\hline
\end{tabular}

Values of the results are expressed as mean \pm standard deviation of three independent experiments TPC total phenolics contents (mg GAE/g extract); TFC total flavonoids contents (mg QE/g extract); TE total extract, $H E$ hexane fraction, $E F$ ethyl acetate fraction, $M F$ methanol fraction; $D P P H$ radical scavenging assay $\left(\mathrm{IC}_{50} \mu \mathrm{g} \mathrm{ml}^{-1}\right) ; P R A$ phosphomolybdenum reduction assay (mg $\alpha \mathrm{TE} / \mathrm{g}$ extract) 
samples showed less antioxidant activities (ranged from $\mathrm{IC}_{50}$ 30.2 to $122.9 \mu \mathrm{g} \mathrm{ml}^{-1}$ ) than the roots. The maximum radical scavenging activities were detected for RMF and RTE $\left(\mathrm{IC}_{50}\right.$ 9.2 and $10.0 \mu \mathrm{g} \mathrm{ml}^{-1}$ ). These values were comparable to $\mathrm{IC}_{50}$ values of the two standard antioxidant agents BHT and vitamin $\mathrm{E}$ (7.8 and $14.2 \mu \mathrm{g} \mathrm{ml}^{-1}$, respectively) in this study.

In phosphomolybdenum reduction assay (PRA), root samples revealed stronger antioxidant abilities. In the roots, RMF and REF were the most powerful antioxidants (1011 and $960 \mathrm{mg} \alpha \mathrm{TE} / \mathrm{g}$ extract, respectively). Also, in leaves, LTE and LMF had the highest antioxidant activities (571 and 559, respectively). These results show that $R$. hyrcanus roots can be considered as a potent natural antioxidant for the replacement of synthetic ones.

By comparing the antioxidant activities of leaves and roots, it was obvious that the roots had a higher level of antioxidant activity in both assays. Regarding this, it can be suggested that the antioxidant effect depends on the type of tissue as a result of different phytochemical contents [45]. The antioxidant activities of leaves and roots of $R$. hyrcanus can be related to the high amounts of phenolic and flavonoid compounds [26]. The methanol fraction and total extract of roots and leaves, which showed the best antioxidant activities, had the highest contents of total phenolics and total flavonoids.

Additionally, correlations and regression analyses were carried out between total phenolics and flavonoid contents and antioxidant capacities of $R$. hyrcanus roots and leaves. The DPPH radical scavenging test exhibited negative correlations and regressions with the phenolic and flavonoid contents. Given that in DPPH antioxidant assay, the results are calculated as $\mathrm{IC}_{50}$ values, the lower amount is representing higher radical scavenging action and vice versa [34].

The phenolic contents were significantly correlated with the DPPH radical scavenging activities in leaves and roots and influenced them (with $r=-0.905, R^{2}=0.829$, $p=0.047$ for leaves; $r=-0.987, R^{2}=0.973, p=0.007$ for roots). Although the leaf flavonoid contents showed a notable correlation with radical scavenging effect $(r=-0.977$, $\left.R^{2}=0.954, p=0.011\right)$, it did not exhibit a significant correlation in roots $\left(r=-0.859, R^{2}=0.737, p=0.071\right)$. Interestingly, the phenolics contents in leaves and roots highly influenced the antioxidant abilities in phosphomolybdenum reduction assay (PRA) $\left(r=0.983, R^{2}=0.967, p=0.008\right.$; $r=0.911, R^{2}=0.829, p=0.045$, respectively). However, the root flavonoids content did not significantly correlate with the antioxidant effect in PRA $\left(r=0.649, R^{2}=0.4216\right.$, $p=0.175$ ).

Previous studies have demonstrated the antioxidant capacity of Rubus sp. In a study, Muniyandi et al. showed that the DPPH antioxidant activities of different fractions prepared from the fruits of $R$. niveus, R. ellipticus, and $R$. fairholmianus ranged from 12.5 to $352.1,11.0$ to 272.8 , and 21.2 to $406.8 \mu \mathrm{g} \mathrm{ml}^{-1}$, respectively [34]. They also revealed that methanol and ethyl acetate were the best solvents for extracting antioxidant phytochemicals [34]. Grochowski et al. investigated the radical scavenging activity of $R$. caesius. Their results indicated that the $\mathrm{IC}_{50}$ values of different fractions ranged between 44.5 and $240.9 \mu \mathrm{g} \mathrm{ml}^{-1}$, and the ethyl acetate fraction had the best activity [50]. Veljkovic et al. reported that $\mathrm{IC}_{50}$ values for leaf methanol extracts of different populations of $R$. idaeus ranged from 110.2 to $199.2 \mu \mathrm{g} \mathrm{ml}^{-1}$ [45]. Moreover, the studies carried out on root fractions of $R$. fairholmianus revealed a wide range of antioxidant properties $\left(\mathrm{IC}_{50}\right.$ from 3.6 to $27.8 \mu \mathrm{g} \mathrm{ml}^{-1}$ ) [19].

\section{Cytotoxicity}

In this study, the MTT assay was carried out to evaluate the cytotoxic effects of total extracts and fractions prepared from roots and leaves of $R$. hyrcanus on MCF-7 and HU02 cell lines. Both cell lines were treated by each sample at different concentrations for $48 \mathrm{~h}$. The total extract of leaves and roots inhibited the proliferation of MCF-7 in a dosedependent manner with the $\mathrm{IC}_{50}$ of 392 and $414 \mu \mathrm{g} \cdot \mathrm{ml}^{-1}$, respectively. Among the fractions, the REF and LEF had the strongest cytotoxic activities on MCF-7 cell line $\left(\mathrm{IC}_{50}\right.$ : 247 and $227 \mu \mathrm{g} \mathrm{ml}^{-1}$, respectively). The anti-proliferative activities of samples on normal cell line were not considerable $\left(>1000 \mu \mathrm{g} \mathrm{ml}^{-1}\right)$ (Table 2).

The selectivity index (SI) depicted the concentration of plant samples resulting in a $50 \%$ reduction of viability of the normal cell line to the concentration that can reduce $50 \%$ viability of cancerous cells. This index is used for the
Table 2 Cytotoxic activities $\left(\mathrm{IC}_{50}\right.$ values) and selectivity indexes of total extracts and fractions from leaves and roots of $R$. hyrcanus on MCF-7 (breast cancer) cell line and HU02 (normal cell line) cells

\begin{tabular}{|c|c|c|c|c|c|c|}
\hline \multirow[t]{2}{*}{ Sample } & \multicolumn{2}{|c|}{$\begin{array}{l}\text { MCF-7 } \\
\left(\mathrm{IC}_{50} \text { value } \mu \mathrm{g} \mathrm{ml}^{-1}\right)\end{array}$} & \multicolumn{2}{|c|}{$\begin{array}{l}\text { HU02 } \\
\left(\text { IC }_{50} \text { value } \mathrm{mg} \mathrm{ml}^{-1}\right)\end{array}$} & \multicolumn{2}{|c|}{ Selectivity index } \\
\hline & Leaves & Roots & Leaves & Roots & Leaves & Roots \\
\hline $\mathrm{TE}$ & $392 \pm 2$ & $414 \pm 2$ & $1.0 \pm 0.3$ & $1.1 \pm 0.2$ & 2.6 & 2.7 \\
\hline $\mathrm{HF}$ & $620 \pm 1$ & $471 \pm 2$ & $1.6 \pm 0.4$ & $1.1 \pm 0.3$ & 2.5 & 2.3 \\
\hline $\mathrm{EF}$ & $227 \pm 1$ & $247 \pm 1$ & $1.2 \pm 0.3$ & $1.2 \pm 0.4$ & 5.3 & 4.7 \\
\hline MF & $315 \pm 2$ & $325 \pm 1$ & $1.3 \pm 0.4$ & $1.1 \pm 0.6$ & 4.2 & 3.4 \\
\hline
\end{tabular}

$T E$ total extract, $H E$ hexane fraction, $E F$ ethyl acetate fraction, $M F$ methanol fraction 
evaluation of the safety and efficacy of various substances. References consider the SI higher than three to be more selective toward cancerous cell lines than normal cells. In this study, EF prepared from roots and leaves showed the highest selectivity indexes (4.73 and 5.31, respectively) which depict the safety of these fractions.

So far, the growth inhibitory effects of numerous Rubus species have been reported. For instance, the methanol extract from leaves of $R$. idaeus indicated cytotoxic activity $\left(\mathrm{IC}_{50} 95.7 \mu \mathrm{g} \mathrm{ml}^{-1}\right.$ ) on HCT-116 (Human colorectal cancer cell line) [45]. Jazić et al. showed that the fruits of $R$. fruticosus had anti-proliferative activity against MCF-7 and Hela (cervix epitheloid carcinoma) cell lines with $\mathrm{IC}_{50}$ of 306.7 and $315.5 \mu \mathrm{g} \mathrm{ml}^{-1}$, respectively [51]. In another study, Plackal Adimuriyil et al. revealed that the root extract of $R$. fairholmianus had antitumor activity on human colorectal cancer cell (Caco-2), suggesting that it can cause a significant decline in the cell viability and proliferation, as well as inducing apoptotic activity [52].

Acetone and methanol extracts of $R$. ellipticus represented strong anticancer properties against human cervical cancer cells (C33A) $\left(\mathrm{IC}_{50}=500\right.$ and $490 \mu \mathrm{g} \mathrm{ml}^{-1}$, respectively), while displaying no anti-proliferative activities on normal PBMCs cells [6]. These results are correlated with the results of our research. Recent research demonstrated the relationship between the antioxidative effects and the anticarcinogenic, antimutagenic capacities of polyphenols, which play a critical role in protecting against cellular oxidative damage [34]. In this study, the total extract, ethyl acetate, and methanol fractions of both roots and leaves, which contained a high amount of phenolic compounds, revealed the best $\mathrm{IC}_{50}$ values against MCF-7, but no correlation was found between the values of phenolics content and the potency of anti-proliferative activities. Therefore, more investigation is needed to clarify the mechanism of cytotoxicity.

\section{Antibacterial activity}

The antibacterial activities of different extracts from roots and leaves of $R$. hyrcanus are shown in Table 3. All the prepared extracts did not show any antibacterial activities against Gram-negative bacteria, including E. coli and P. aeruginosa, except LTE and LMF, which had weak activities against $E$. coli (zone of inhibition 7 and $8 \mathrm{~mm}$, respectively). The root total extract and fractions showed antibacterial activities on $S$. aureus and B. subtilis (zone of inhibition 10.0-16.5 mm and 14-20 mm, respectively). The LTE, LEF, and LMF had lower antibacterial effect on $S$. aureus (zone of inhibition 10.5-11.5 mm) than roots. Moreover, only LTE and LMF were effective against $B$. subtilis (zone of inhibition 11.5 and $15.5 \mathrm{~mm}$, respectively).

The $B$. subtilis indicated the best sensitivity rate to the tested samples (MIC ranged from 1.5 to $6.3 \mathrm{mg} \mathrm{m}^{-1}$ ). The highest anti- $B$. subtilis activities were determined by RTE and RMF (MIC $1.5 \mathrm{mg} \mathrm{ml}^{-1}$ ), followed by LMF and LTE (MIC $3.1 \mathrm{mg} \mathrm{ml}^{-1}$ ). Moreover, the most effective samples against $S$. aureus were RMF and RTE (MIC $1.5 \mathrm{mg} \mathrm{ml}^{-1}$ ).

Thiem et al. reported that the $R$. chamaemorus butanol fraction showed antibacterial activity against Gram-positive and Gram-negative bacteria (MIC 0.58 to $2.33 \mathrm{mg} \mathrm{ml}^{-1}$ ) and the most sensitive bacteria were $S$. aureus and B. subtilis [53] which are comparable to the results of our study. In another study, Grabek-Lejko et al. demonstrated that $R$. plicatus leaves and fruits had antibacterial effects on different strains of S. aureus, mainly against methicillin-resistant ones (MRSA) [54]. Also, the acetone extract from roots of $R$. fairholmianus had antibacterial activity against $S$. aureus
Table 3 Antibacterial activity of total extracts and fractions from leaves and roots of Rubus hyrcanus

\begin{tabular}{|c|c|c|c|c|c|c|}
\hline \multirow[t]{2}{*}{ Sample } & \multicolumn{2}{|l|}{ S.aureus } & \multicolumn{2}{|l|}{ B. subtilis } & \multicolumn{2}{|c|}{ E. coli } \\
\hline & ZI & MIC & ZI & MIC & ZI & MIC \\
\hline \multicolumn{7}{|l|}{ Leaves } \\
\hline $\mathrm{TE}$ & $10.5 \pm 1.0$ & 3.1 & $11.5 \pm 1.5$ & 3.1 & 7 & 100 \\
\hline $\mathrm{HF}$ & - & - & - & - & - & - \\
\hline $\mathrm{EF}$ & $11.0 \pm 1.0$ & 25 & - & - & - & - \\
\hline MF & $11.5 \pm 1.0$ & 3.1 & $15.5 \pm 1.2$ & 3.1 & 8 & 100 \\
\hline \multicolumn{7}{|l|}{ Roots } \\
\hline $\mathrm{TE}$ & $14.3 \pm 0.6$ & 1.5 & 20 & 1.5 & - & - \\
\hline $\mathrm{HF}$ & 10 & 50 & 14 & 6.3 & - & - \\
\hline $\mathrm{EF}$ & 10 & 12.5 & 14 & 6.3 & - & - \\
\hline MF & $16.5 \pm 0.6$ & 1.5 & 20 & 1.5 & - & - \\
\hline
\end{tabular}

The results are expressed as the mean \pm SD

$T E$ total extract, $H E$ hexane fraction, $E F$ ethyl acetate fraction, $M F$ methanol fraction; $Z I$ zone of inhibition (mm) $M I C$ minimum inhibitory concentration $\left(\mathrm{mg} \mathrm{ml}^{-1}\right)$

- No bacterial activity found 
with MIC of $337.86 \mu \mathrm{g} \mathrm{ml}^{-1}$ [48]. Assafiri et al. reported that leaves of $R$. canescens had bactericidal effect against MRSA (zone of inhibition $34 \mathrm{~mm}$ ) [55].

Jang et al. showed that different fractions of $R$. coreanus roots had effective antibacterial actions on $B$. subtilis and $S$. aureus (MIC 5 and $30 \mathrm{mg} \mathrm{ml}^{-1}$ ) [56].

The extraction of bioactive phytochemicals from plant species is mainly related to the type of solvent used in the extraction process [57]. In the present study, three solvents including hexane, ethyl acetate, and methanol were used for fractionation of total extracts. According to the results, methanol was the best solvent for extracting phytochemicals with the highest antibacterial activity. This finding is consistent with other researches that reported methanol and ethanol as the best solvents for extracting antimicrobial phytochemicals from the plants [57-59]. In the present study, methanol fractions of roots and leaves contained the highest amounts of total phenolic compounds. The different investigations demonstrated the antibacterial effects of polyphenols against wide ranges of bacteria [60]. These compounds exert their activities due to several suggested mechanisms, including damaging the cell membrane, inhibiting intracellular enzymes, decreasing host ligands adhesion, suppressing biofilm formation, neutralizing bacterial toxins, and having the synergic effects with other antibiotics $[17,60]$.
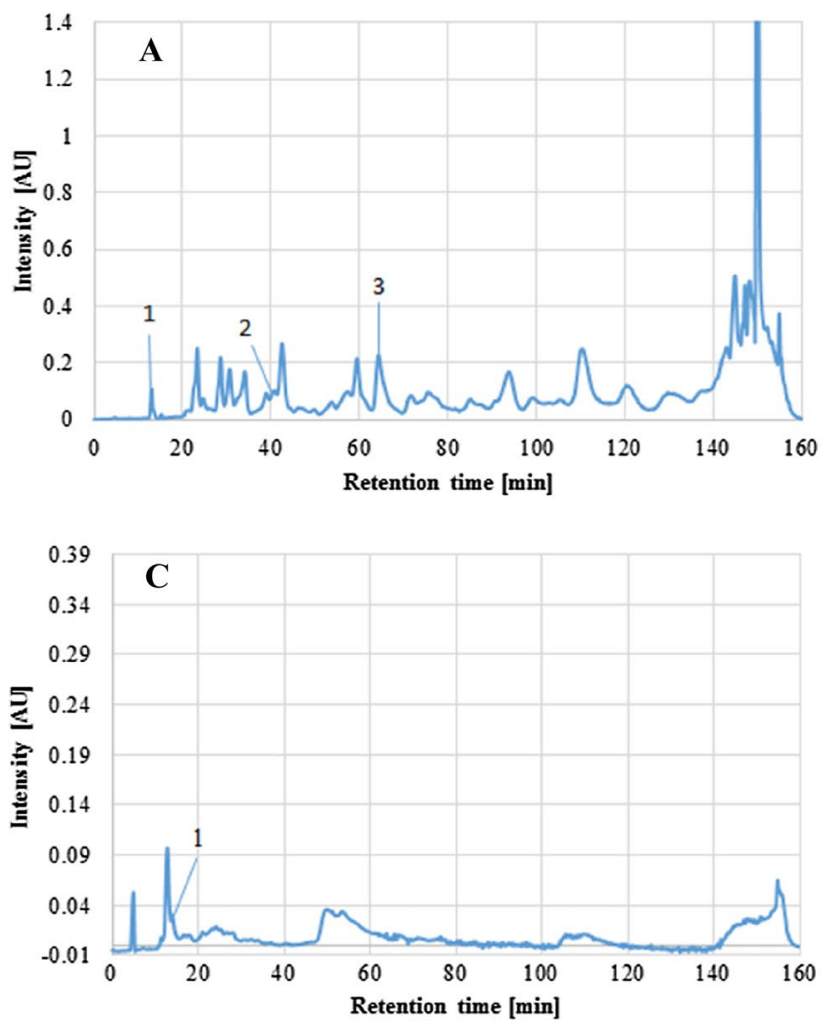

\section{HPLC-DAD and LC-MS/MS analysis}

Among the samples, four fractions with the most significant biological activities (REF, RMF, LEF, and LMF) were chosen for DAD-HPLC analysis. For the identification of main compounds, twenty standards were used. Compounds were identified according to their retention times and absorbance spectra. The HPLC chromatographic profiles of phenolic compounds in the fractions REF, RMF, LEF, and LMF are shown in the Fig. 1.

In addition, LC-MS/MS analysis was utilized to identify the presence of unknown compounds by matching their molecular and fragmentation ions with the literature data. The different chromatograms of $R$. hyrcanus extracts from leaves and roots indicated that the compositions of polyphenols vary in the different parts of the plant.

In the LEF of the R. hyrcanus, from 20 phenolic compounds used as external standards, only gallic acid, $p$-coumaric acid, and chlorogenic acid were detected (Fig. 1). As is presented in Table 4, gallic acid had the highest concentration of $7.50 \mathrm{mg} \mathrm{g}^{-1}$, followed by $p$-coumaric acid (5.67 $\mathrm{mg} \mathrm{g}^{-1}$ ), while chlorogenic acid had the lowest concentration $\left(0.65 \mathrm{mg} \mathrm{g}^{-1}\right)$. The rest of the peaks could not be identified. In contrast, in LMF, chlorogenic acid was
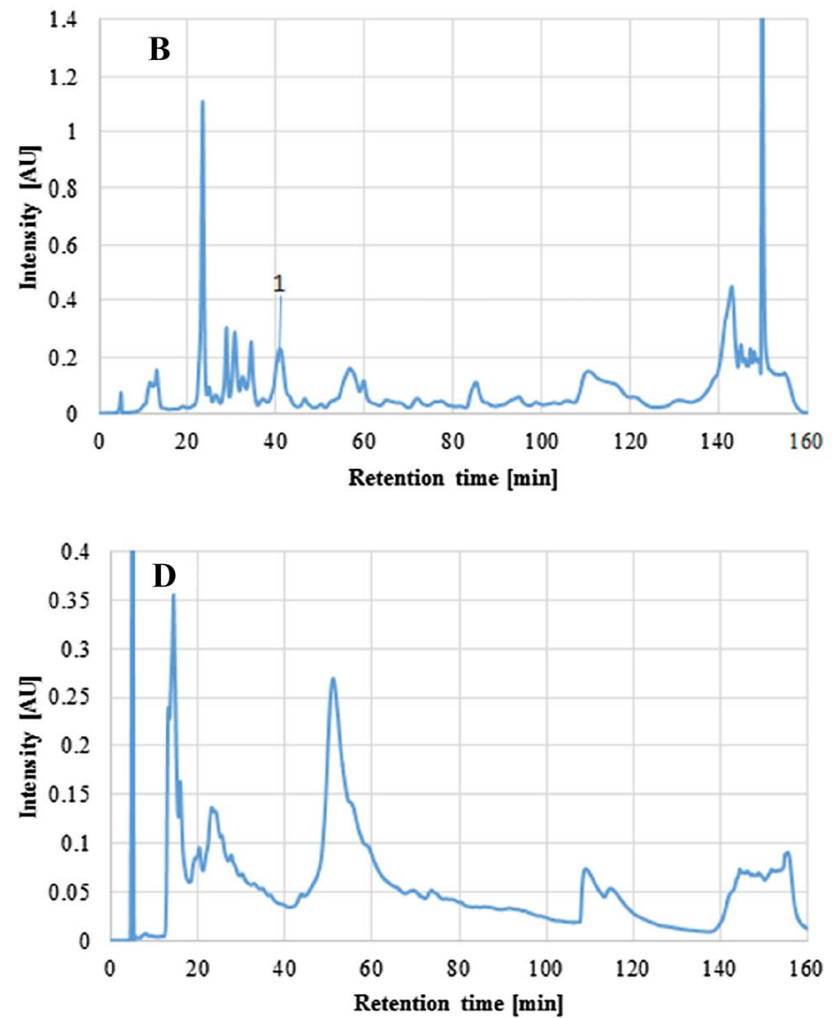

Fig. 1 HPLC chromatograms of R. hyrcanus at $320 \mathrm{~nm}$ : A leaves ethyl acetate fraction, gallic acid (1), chlorogenic acid (2), and $p$-coumaric acid (3); B leaves methanol fraction, chlorogenic acid (1); C root ethyl acetate fraction, gallic acid (1); D Root methanol fraction 
Table 4 Polyphenols in roots and leaves of Rubus hyrcanus

\begin{tabular}{llll}
\hline Polyphenol & Gallic acid & $p$-Coumaric acid & Chlorogenic acid \\
\hline Leaves & & & \\
EF & $7.50 \pm 0.69$ & $5.67 \pm 0.19$ & $0.65 \pm 0.05$ \\
MF & n.d. & n.d. & $2.97 \pm 0.17$ \\
Roots & & & \\
EF & $15.6 \pm 1.3$ & n.d. & n.d. \\
MF & n.d. & n.d. & n.d. \\
\hline
\end{tabular}

Results are expressed as mean $\pm \mathrm{SD}$

$E F$ ethyl acetate fraction, $M F$ methanol fraction, concentration: $\mathrm{mg} / \mathrm{g}$ extract

n.d. not detected

detected at the concentration of $2.97 \mathrm{mg} \mathrm{g}^{-1}$, but gallic acid and $p$-coumaric acid were not detected.

The HPLC analysis of REF revealed that the amount of gallic acid was $15.6 \mathrm{mg} \mathrm{g}^{-1}$, but none of the other compounds were found in this fraction. In the RMF all the peaks remained unknown.
The presence of chlorogenic acid was also confirmed by LC-MS/MS analysis (Fig. 2). The chlorogenic acid is an esterified form of caffeic acid and quinic acid [61]. This results in cleavage of intact caffeoyl and quinic acid fragments as a fragmentation pattern in APCI MS with negative ion mode. This could be confirmed by MS, by which the same $[\mathrm{M}-1]^{-}$ion at $\mathrm{m} / \mathrm{z}, 353$ was detected in the multiple ion scan. In the multiple reactions monitoring (MRM), a peak at $\mathrm{m} / \mathrm{z} 191$ was detected, confirming that chlorogenic acid decomposes into quinic acid and caffeic acid by fragmentation. This is in agreement with the results of Fang et al. [61]. It also showed a $[\mathrm{M}-1]^{-}$ion at $\mathrm{m} / \mathrm{z}$ 447. Also, MRM determined a product ion at $\mathrm{m} / \mathrm{z}$ 285 , which is why the presence of luteolin-7-O-glucoside could be assumed (Fig. 2). However, a comparison of the wavelength of maximum absorbance with the reference substance disproved this. The fact that the same fragment was also detected by MRM suggests that the glucoside is linked to luteolin at a different position, or there is a linkage of another glucoside with the same mass. Further LC-MS/MS analysis showed various peaks in the 200-600 scan range. It showed a $[\mathrm{M}-1]^{-}$ion at $\mathrm{m} / z 431$ and 461.1.

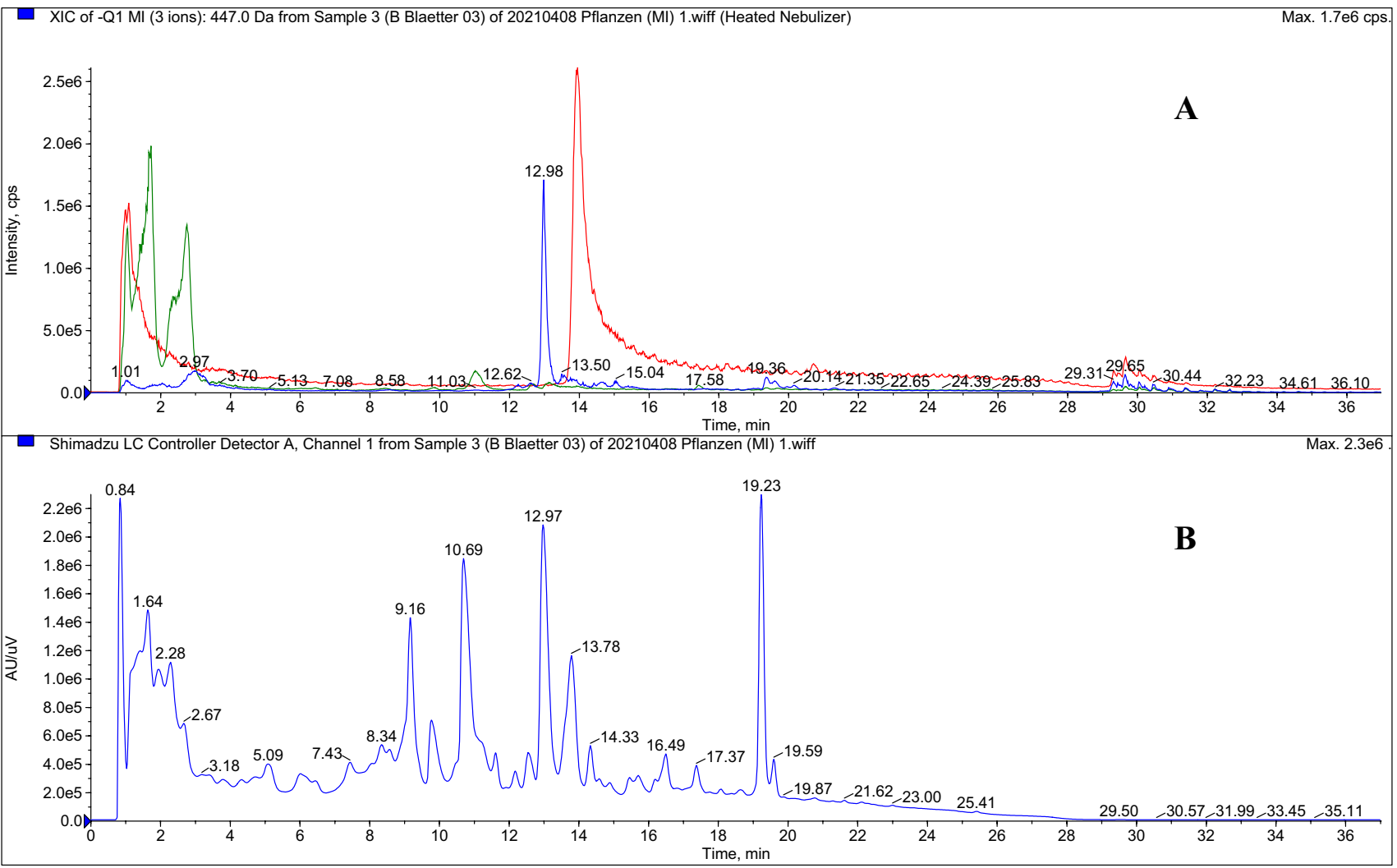

Collected by: BO-MS \Administrator Operator: Administrator

Fig. 2 A APCI LC-MS/MS, multiple ion scan of Rubus hyrcanus leaves, chlorogenic acid (green) at m/z 353, unknown luteolin-glucoside (blue) at $\mathrm{m} / \mathrm{z} 447$; B HPLC-UV (280 nm) chromatogram of Rubus hyrcanus leaves, unknown luteolin-glucoside at $t_{r}=12.97 \mathrm{~min}$ 
The latter could represent kaempferol-7-O-hexuronide [44]. An exact assignment via the mass was not possible.

Gudej et al. revealed that the leaves of Rubus species are rich sources of flavonoids (especially quercetin and kaempferol) and the ellagic acid as a phenolic acid [22]. These compounds could not be demonstrated in the extracts of $R$. hyrcanus. Martini et al. reported a number of phenolic compounds, including flavonoids and phenolic acids like caffeic acid, ferulic acid, and gallic acid in $R$. ulmifolius leaves. The amount of gallic acid in this study was $0.062 \mathrm{mg} / \mathrm{g}$, which is lower than the reported amount in the present study [47].

Oszmianski et al. showed that chlorogenic acid had a concentration between $0.19 \mathrm{mg} \mathrm{g}^{-1}$ and $6.34 \mathrm{mg} \mathrm{g}^{-1}$ in the dry matter of blackberry leaves of various species [62]. This finding is consistent with the amount of chlorogenic acid in our study $\left(2.97 \pm 0.17 \mathrm{mg} . \mathrm{g}^{-1}\right)$, which is in the middle of range.

\section{Conclusions}

This study focused on phytochemical analysis, antioxidant, cytotoxic, and antibacterial activities of total extracts and different fractions from the roots and leaves of Rubus hyrcanus (family Rosaceae). It was determined that the root extracts of $R$. hyrcanus had the higher amount of total phenolic contents as well as better antioxidant activity rather than leaves. The ethyl acetate fractions of roots and leaves had the best cytotoxic activities on MCF-7 cell line with the best selectivity indexes. All the extracts and fractions showed better antibacterial activity against Grampositive bacteria rather than Gram-negative ones. Also, the roots samples had more potent antibacterial activity than leaves. In phytochemical analysis, gallic acid was detected in leaves and roots. In leaves, p-coumaric acid and chlorogenic acid were also identified. The HPLC peaks in methanol fraction of roots remained unknown. Considering all results, the roots of $R$. hyrcanus are an interesting raw material for bioactive plant products.

Acknowledgements This work was supported by Guilan University of Medical Sciences (Grant No. 99080506). Thanks are given to Angelika Malarski, Institute of Nutritional Sciences, Friedrich Schiller University Jena, for technical assistance.

Funding Open Access funding enabled and organized by Projekt DEAL.

\section{Declarations}

Conflict of interest The authors declare no conflict of interest.
Ethical approval This article does not contain any studies with human or animal subjects.

Open Access This article is licensed under a Creative Commons Attribution 4.0 International License, which permits use, sharing, adaptation, distribution and reproduction in any medium or format, as long as you give appropriate credit to the original author(s) and the source, provide a link to the Creative Commons licence, and indicate if changes were made. The images or other third party material in this article are included in the article's Creative Commons licence, unless indicated otherwise in a credit line to the material. If material is not included in the article's Creative Commons licence and your intended use is not permitted by statutory regulation or exceeds the permitted use, you will need to obtain permission directly from the copyright holder. To view a copy of this licence, visit http://creativecommons.org/licenses/by/4.0/.

\section{References}

1. Newsholme P, Cruzat VF, Keane KN, Carlessi R, de Bittencourt Jr PIH (2016) Molecular mechanisms of ROS production and oxidative stress in diabetes. Biochem J 473(24):4527-4550

2. Schieber M, Chandel Navdeep S (2014) ROS function in redox signaling and oxidative stress. Curr Biol 24(10):R453-R462

3. Betteridge DJ (2000) What is oxidative stress? Metabolism 49(2):3-8 (Supplement 1)

4. Aruoma OI (1998) Free radicals, oxidative stress, and antioxidants in human health and disease. J Am Oil Chem Soc 75(2):199-212

5. Gutteridge J (1993) Free radicals in disease processes-a compilation of cause and consequence. Invited Rev Free Radic Res Commun 19:141-158

6. Saini R, Dangwal K, Singh H, Garg V (2014) Antioxidant and antiproliferative activities of phenolics isolated from fruits of Himalayan yellow raspberry (Rubus ellipticus). J Food Sci Technol 51(11):3369-3375

7. Jacob RA (1995) The integrated antioxidant system. Nutr Res 15(5):755-766

8. Sharififar F, Dehghn-Nudeh G, Mirtajaldini M (2009) Major flavonoids with antioxidant activity from Teucrium polium $\mathrm{L}$. Food Chem 112(4):885-888

9. Al-Juhaimi F, Ghafoor K, Özcan MM, Jahurul MHA, Babiker EE, Jinap $S$ et al (2018) Effect of various food processing and handling methods on preservation of natural antioxidants in fruits and vegetables. J Food Sci Technol 55(10):3872-3880

10. Haminiuk CW, Maciel GM, Plata-Oviedo MS, Peralta RM (2012) Phenolic compounds in fruits-an overview. Int J Food Sci Technol 47(10):2023-2044

11. Han X, Shen T, Lou H (2007) Dietary polyphenols and their biological significance. Int J Mol Sci 8(9):950-988

12. Frei B, Higdon JV (2003) Antioxidant activity of tea polyphenols in vivo: evidence from animal studies. J Nutr 133(10):3275S-3284S

13. Nabavi SF, Di Lorenzo A, Izadi M, Sobarzo-Sánchez E, Daglia M, Nabavi SM (2015) Antibacterial effects of cinnamon: from farm to food, cosmetic and pharmaceutical industries. Nutrients 7(9):7729-7748

14. Zhu H-1, Chen G, Chen S-n, Wang Q-r, Wan L, Jian S-p (2019) Characterization of polyphenolic constituents from Sanguisorba officinalis L. and its antibacterial activity. Eur Food Res Technol 245(7):1487-1498

15. Nedorostova L, Kloucek P, Kokoska L, Stolcova M, Pulkrabek J (2009) Antimicrobial properties of selected essential 
oils in vapour phase against foodborne bacteria. Food Control 20(2): 157-160

16. Fazlara A, Ekhtelat M (2012) The disinfectant effects of benzalkonium chloride on some important foodborne pathogens. Am Eurasian J Agric Environ Sci 12(1):23-29

17. Bouarab-Chibane L, Forquet V, Lantéri P, Clément Y, LéonardAkkari L, Oulahal N, et al (2019) Antibacterial properties of polyphenols: characterization and QSAR (quantitative structure-activity relationship) models. Front Microbiol 10:829

18. Deighton N, Brennan R, Finn C, Davies HV (2000) Antioxidant properties of domesticated and wild Rubus species. J Sc Food Agric 80(9):1307-1313

19. Plackal George B, Thangaraj P, Sulaiman C, Piramanayagam S, Ramaswamy SK (2014) Bioassay directed isolation and biological evaluation of compounds isolated from Rubus fairholmianus gard. Biomed Res Int 2014:204340

20. Sedighi E, Rahimmalek M (2015) Evaluation of genetic diversity of Rubus hyrcanus using inter simple sequence repeat (ISSR) and morphological markers. Biologia 70(3):339-348

21. Patel A, Rojas-Vera J, Dacke C (2004) Therapeutic constituents and actions of Rubus species. Curr Med Chem 11(11):1501-1512

22. Gudej J, Tomczyk M (2004) Determination of flavonoids, tannins and ellagic acid in leaves from Rubus L. species. Arch Pharm Res 27(11):1114-1119

23. Venskutonis PR, Dvaranauskaite A, Labokas J (2007) Radical scavenging activity and composition of raspberry (Rubus idaeus) leaves from different locations in Lithuania. Fitoterapia 78(2):162-165

24. Verma R, Gangrade T, Punasiya R, Ghulaxe C (2014) Rubus fruticosus (blackberry) use as an herbal medicine. Pharmacogn Rev 8(16): 101

25. Riaz M, Ahmad M, Rahman N (2011) Antimicrobial screening of fruit, leaves, root and stem of Rubus fruticosus. J Med Plants Res 5(24):5920-5924

26. Yousefbeyk F, Vatandoost H, Golfakhrabadi F, Mirzaee Z, Abai MR, Amin G et al (2018) Antioxidant and larvicidal activity of areal parts of Scrophularia striata against malaria vector Anopheles stephensi. J Arthropod Borne Dis 12(2):119-126

27. Sayad-Fathi S, Zaminy A, Babaei P, Yousefbeyk F, Azizi N, Nasiri E (2020) The methanolic extract of Cinnamomum zeylanicum bark improves formaldehyde-induced neurotoxicity through reduction of phospho-tau (Thr231), inflammation, and apoptosis. EXCLI J 19:671-686

28. Hamidi M, Ghasemi S, Bavafa Bighdilou B, Eghbali Koohi D (2020) Evaluation of antioxidant, antibacterial and cytotoxic activity of methanol extract from leaves and fruits of Iranian squirting cucumber (Ecballium elaterium (L.) A. rich). Res J Pharmacogn 7(1):23-29

29. Golfakhrabadi F, Yousefbeyk F, Mirnezami T, Laghaei P, Hajimahmoodi M, Khanavi M (2015) Antioxidant and antiacetylcholinesterase activity of Teucrium hyrcanicum. Pharmacogn Res 7(Suppl 1):S15-S19

30. Saeidnia SGA (2012) Pharmacognosy and molecular pharmacognosy in practice: a laboratory desk reference of pharmacognosy for researchers and students. Saarbrücken. Lambert Academic Publishing, Germany

31. Yousfbeyk F, Esmaiili T, Pashna Z, Hozori Z, Ghohari A, Ostad S et al (2014) Antioxidant activity, total phenol and total anthocyanin contents of Cornus sanguinea L. subsp australis. (CA Mey.) Jáv. J Med Plants 13(49):69-74

32. Tofighi Z, Alipour F, Hadavinia H, Abdollahi M, Hadjiakhoondi A, Yassa N (2014) Effective antidiabetic and antioxidant fractions of Otostegia persica extract and their constituents. Pharm Biol 52(8):961-966
33. Nibir YM, Sumit AF, Akhand AA, Ahsan N, Hossain MS (2017) Comparative assessment of total polyphenols, antioxidant and antimicrobial activity of different tea varieties of Bangladesh. Asian Pac J Trop Biomed 7(4):352-357

34. Muniyandi K, George E, Sathyanarayanan S, George BP, Abrahamse H, Thamburaj S et al (2019) Phenolics, tannins, flavonoids and anthocyanins contents influenced antioxidant and anticancer activities of Rubus fruits from Western Ghats. India Food Sci Hum Wellness 8(1):73-81

35. Demirci MA, Ipek Y, Gul F, Ozen T, Demirtas I (2018) Extraction, isolation of heat-resistance phenolic compounds, antioxidant properties, characterization and purification of 5-hydroxymaltol from Turkish apple pulps. Food Chem 269:111-117

36. Yousefbeyk F, Tabaside J, Ostad S, Salehi Sourmaghi M, Amin G (2016) Investigation of chemical composition and cytotoxic activity of aerial parts of Ziziphora clinopodioides Lam. Res J Pharmacogn 3(2):47-51

37. Ghasemi S, Davaran S, Sharifi S (2013) Comparison of cytotoxic activity of L778123 as a farnesyltranferase inhibitor and doxorubicin against A549 and HT-29 cell lines. Adv Pharm Bull 3(1):73

38. Azmian Moghadam F, Evazalipour M, Ghasemi S, Kefayati H (2020) Design, synthesis, biological evaluation and docking study of novel 4-anilinoquinazolines derivatives as anticancer agents. Iran J Chem Chem Eng (in press).

39. Moghadam FA, Evazalipour M, Kefayati H, Ghasemi S (2021) 6, 7-disubstituted-4-anilinoquinazoline: design, synthesis and anticancer activity as a novel series of potent anticancer agents. Pharm Sci 27(2):209-218

40. Kiehlbauch JA, Hannett GE, Salfinger M, Archinal W, Monserrat C, Carlyn C (2000) Use of the National Committee for Clinical Laboratory Standards guidelines for disk diffusion susceptibility testing in New York state laboratories. J Clin Microbiol 38(9):3341-3348

41. Golfakhrabadi F, Ardekani MRS, Saeidnia S, Yousefbeyk F, Jamalifar H, Ramezani N et al (2016) Phytochemical analysis, antimicrobial, antioxidant activities and total phenols of Ferulago carduchorum in two vegetative stages (flower and fruit). Pak J Pharm Sci 29(2):623-628

42. Kschonsek J, Wolfram T, Stöckl A, Böhm V (2018) Polyphenolic compounds analysis of old and new apple cultivars and contribution of polyphenolic profile to the in vitro antioxidant capacity. Antioxidants 7(1):20

43. Ernawita, Westphal A, Malarski A, Böhm V (2019) Polyphenols, vitamin $\mathrm{C}$, in vitro antioxidant capacity, $\alpha$-amylase and COX-2 inhibitory activities of citrus samples from Aceh, Indonesia. Int J Vitam Nutr Res 89(5-6):337-347

44. Pavlović AV, Papetti A, Zagorac DČD, Gašić UM, Mišić DM, Tešić ŽL et al (2016) Phenolics composition of leaf extracts of raspberry and blackberry cultivars grown in Serbia. Ind Crops Prod 87:304-314

45. Veljkovic B, Djordjevic N, Dolicanin Z, Licina B, Topuzovic M, Stankovic M et al (2019) Antioxidant and anticancer properties of leaf and fruit extracts of the wild raspberry (Rubus idaeus L.). Not Bot Horti Agrobot Cluj-Napoca 47(2):359-367

46. Asnaashari M, Tajik R, Khodaparast MHH (2015) Antioxidant activity of raspberry (Rubus fruticosus) leaves extract and its effect on oxidative stability of sunflower oil. J Food Sci Technol 52(8):5180-5187

47. Martini S, D'Addario C, Colacevich A, Focardi S, Borghini F, Santucci A et al (2009) Antimicrobial activity against Helicobacter pylori strains and antioxidant properties of blackberry leaves (Rubus ulmifolius) and isolated compounds. Int J Antimicrob Agents 34(1):50-59

48. Rajendran NK, George BP, Houreld NN, Abrahamse H (2021) Synthesis of zinc oxide nanoparticles using Rubus fairholmianus 
root extract and their activity against pathogenic bacteria. Molecules 26(10):3029

49. Dores RG, Guimarães SF, Braga TV, Fonseca M, Martins PM, Ferreira TC (2014) Phenolic compounds, flavonoids and antioxidant activity of leaves, flowers and roots of goat weed. Hortic Brasileira 32(4):486-490

50. Grochowski DM, Paduch R, Wiater A, Dudek A, Pleszczyńska $\mathrm{M}$, Tomczykowa $\mathrm{M}$ et al (2016) In vitro antiproliferative and antioxidant effects of extracts from Rubus caesius leaves and their quality evaluation. Evid Based Complementary Altern Med 2016:5698685

51. Jazić M, Kukrić Z, Vulić J, Četojević-Simin D (2019) Polyphenolic composition, antioxidant and antiproliferative effects of wild and cultivated blackberries (Rubus fruticosus L.) pomace. Int J Food Sc Technol 54(1):194-201

52. Plackal Adimuriyil GB, Tynga IM, Abrahamse H (2015) In vitro antiproliferative effect of the acetone extract of Rubus fairholmianus gard. Root Human Colorectal Cancer Cells Biomed Res Int 2015:165037

53. Thiem B, Goślińska O (2004) Antimicrobial activity of Rubus chamaemorus leaves. Fitoterapia 75(1):93-95

54. Grabek-Lejko D, Wojtowicz K (2021) Comparison of antibacterial and antioxidant properties of fruits and leaves of blackberry (Rubus plicatus) and raspberry (Rubus idaeus). J Microbiol Biotechnol Food Sci 3(6):514-518

55. Assafiri O, Abdallah H, El-Dakdouki M (2020) Antibacterial effect and phytochemical analysis of the shoot system of Rubus canescens DC. growing in Lebanon. BAU J Sci Technol 2(1):9
56. Jang HN, Ha JH, Lee YJ, Fu MM, Park SN (2019) Isolation and characterization of bioactive compounds from root of Rubus coreanus Miquel and their antimicrobial activity. Microbiol Biotechnol Lett 47(1):54-63

57. Panda SK, Mohanta YK, Padhi L, Luyten W (2019) Antimicrobial activity of select edible plants from Odisha, India against foodborne pathogens. LWT-Food Sci Technol 113:108246

58. Shan B, Cai Y-Z, Brooks JD, Corke H (2007) The in vitro antibacterial activity of dietary spice and medicinal herb extracts. Int J Food Microbiol 117(1):112-119

59. Sunilson JAJ, Suraj R, Rejitha G, Anandarajagopal K, Kumari AAG, Promwichit P (2009) In vitro antimicrobial evaluation of Zingiber officinale, Curcuma longa and Alpinia galanga extracts as natural food preservatives. Am J Food Technol 4(5):192-200

60. Daglia M (2012) Polyphenols as antimicrobial agents. Curr Opin Biotechnol 23(2):174-181

61. Fang N, Yu S, Prior RL (2002) LC/MS/MS characterization of phenolic constituents in dried plums. J Agric Food Chem 50(12):3579-3585

62. Oszmiański J, Wojdyło A, Nowicka P, Teleszko M, Cebulak T, Wolanin M (2015) Determination of phenolic compounds and antioxidant activity in leaves from wild Rubus L. species. Molecules 20(3):4951-4966

Publisher's Note Springer Nature remains neutral with regard to jurisdictional claims in published maps and institutional affiliations. 